18

\title{
Спектрально-кинетическое исследование фотохромных систем на основе наноструктур графена и его оксида
}

\author{
(C) О.В. Венидиктова ${ }^{1}$, В.А. Барачевский ${ }^{1,2,9}$, А.А. Хузин ${ }^{3}$, \\ А.Р. Туктаров ${ }^{3}$, А.И. Шиенок ${ }^{4}$, Н.Л. Зайченко ${ }^{4}$ \\ ${ }^{1}$ Центр фоотохимии ФНИЦ „Кристаллография и фононика“ РАН, \\ 119421 Москва, Россия \\ ${ }^{2}$ Межведомственный центр аналитических исследований при Президиуме РАН, \\ 117997 Москва, Россия \\ ${ }^{3}$ Институт нефтехимии и катализа РАН, \\ 450075 Уфра, Башкортостан, Россия \\ ${ }^{4}$ Институт химической фризики им. Н.Н. Семенова РАН, \\ 119991 Москва, Россия \\ e-mail: barva@photonics.ru
}

Поступила в редакцию 05.06.2019 г.

В окончательной редакции 05.06.2019 г.

Принята к публикации 20.06.2019 г.

\begin{abstract}
Проведено сравнительное спектрально-кинетическое исследование взаимодействия тиолзамещенных молекул диарилэтена и спирооксазина с наночастицами графена и нанопластинками оксида графена. Выявлены различия в фотохромных превращениях соединений, контактирующих с поверхностью углеродных наночастиц в зависимости от структуры соединений и природы наночастиц, свидетельствующие о химическом и физическом взаимодействии молекул фотохромных соединений с поверхностными группами углеродных наноструктур.
\end{abstract}

Ключевые слова: фотохромизм, спирооксазин, диарилэтен, графен, диоксид графена, спектроскопия, кинетика.

DOI: $10.21883 /$ OS.2019.12.48704.207-19

\section{Введение}

В последние годы значительное внимание уделяется исследованию свойств наночастиц графена и его оксида, что обусловлено их высокими значениями электро- и теплопроводности, а также выдающейся механической прочностью, открывающими широкие перспективы их применения в наноэлектронике [1].

Графен является двумерным кристаллом, состоящим из одиночного слоя атомов углерода, собранных в гексагональную решетку. Реакционная способность графена определяется наличием в нем протяженной полиароматической $\pi$-системы и концевыми координационно ненасыщенными атомами углерода, которые обычно связаны c -OH- или (реже) $-\mathrm{CO}_{2} \mathrm{H}$-группами.

Оксид графена (ОГ) - соединение углерода, водорода и кислорода в различных соотношениях, которое образуется при обработке графита сильными окислителями. Наночастицы графена по краям или внутри углеродной сетки имеют кислородсодержащие функциональные группы, в частности гидроксильные, фенольные, карбонильные, карбоксильные, арильные, эфирные, фосфорсодержащие группы.

Наличие поверхностных групп различной природы на поверхности наночастиц графена и ОГ позволяет функционализировать их поверхность различными соединениями за счет ковалентного взаимодействия и изменять их свойства. Однако это взаимодействие может привести и к появлению дефектов на поверхности наночастиц графена и его оксида, ухудшающих их свойства. В связи с этим имеет также важное значение функционализация поверхности этих наночастиц за счет нековалентного, в частности $\pi-\pi$-взаимодействия.

Особый интерес представляет функционализация наночастиц графена и оксида графена фотохромными соединениями, которые могут обеспечить обратимую фотоиндуцированную модуляцию оптических и электрических свойств наночастиц [2]. Фотохромные соединения из класса спиропиранов были использованы для ковалентной и нековалентной функционализации одностенных углеродных нанотрубок с целью создания устройств с фотоуправляемыми оптическими и электрическими свойствами [3-10]. Графен, модифицированный молекулами спиропирана с пиренсодержащим заместителем на длинном спейсере благодаря физическому $\pi-\pi$-взаимодействию оказался пригодным для создания оптических полевых транзисторов [11-14]. С целью использования в биологических исследованиях ОГ был модифицирован молекулами спиропирана, которые обеспечили люминесцентную визуализацию биологических объектов $[15,16]$.

В настоящей работе предпринято исследование спектрального проявления взаимодействия молекул фотохромных соединений из класса термически необратимых 
диарилэтенов и термически релаксирующих спирооксазинов с поверхностью наночастиц графена и его оксида.

Фотохромизм диарилэтенов состоит в обратимой валентной изомеризации открытой формы А в циклическую форму В (схема 1). Эти фотохромные превращения осуществляются только под действием активирующего излучения, поглощаемого соответствующими изомерами.

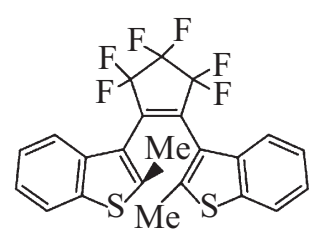

A

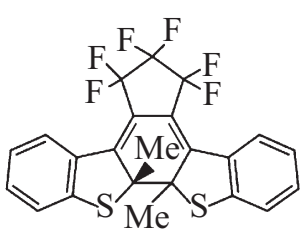

$\mathrm{B}$

Схема 1.

В случае термически релаксирующих спирооксазинов первоначально бесцветные молекулы циклического изомера А под действием УФ излучения в результате фотодиссоциации $-\mathrm{C}-\mathrm{O}-$ связи в пирановом фрагменте и последующей темновой цис-транс-изомеризации испытывают превращение в открытую окрашенную мероцианиновую форму В (схема 2).

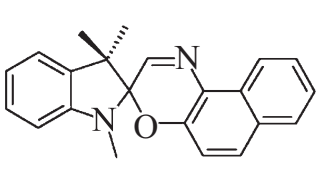

A

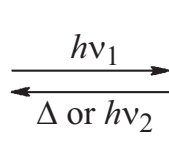

Схема 2.

Возвращение в исходное состояние осуществляется либо спонтанно, либо при облучении видимым светом, поглощаемым мероцианиновой формой. При этом скорость реакции темнового обесцвечивания возрастает при нагревании фотохромной системы.

\section{Экспериментальная часть}

В качестве фотохромных соединений использованы диарилэтен I и спирооксазин II, содержащие тиольные заместители:<smiles>Cc1sc(Cl)cc1C1=C(c2cc(CNc3ccc(S)cc3)sc2C)CCC1</smiles><smiles>Cc1ccc2ccc(OCCCCS)cc2c1N=CC1(C)N(C)c2ccccc2C1(C)C</smiles>

Синтез соединения $\mathbf{I}$ осуществлен реакцией альдегидного производного диарилэтена I' с 4-меркаптоанилином (схема 3).

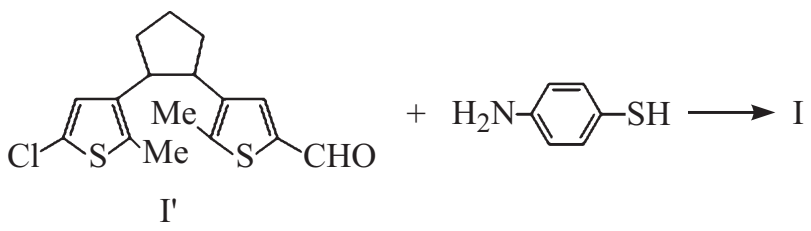

Схема 3.

Альдегидное производное диарилэтена I' синтезировано согласно методике, описанной ранее [17].

Фотохромный спирооксазин II, содержащий тиольную группу [18], синтезирован по схеме 4. Исходный 2,7нафталиндиол (1) был пронитрозирован в уксусной кислоте по положению 1. Полученный 1-интрозо2,7-нафталиндиол (2) был введен в реакцию с 1,3,3триметил-2-метилениндоленином (3) с образованием 1,3-дигидро-9'-гидрокси-1,3,3-триметилспиро[2Н-индол2,3'-[3Н]нафто[2,1-b][1,4]оксазина] (4). Синтезированный спирооксазин был проалкилирован по гидроксигруппе с помощью 1,5-дибромопентана (5) в сухом ацетоне в присутствии карбоната калия с сохранением второго атома брома и образованием 1,3-дигидро-9'-(5бромопентокси)-1,3,3-триметилспиро[2Н-индол-2,3'-[3Н] нафто[2,1-b][1,4]оксазина] (6). Последний в результате воздействия гексаметилдисилатиана, а затем безводного фторида тетрабутиламмония в сухом ТГФ приводил к получению целевого соединения - 1,3-дигидро-9'-(5меркаптопентокси)-1,3,3-триметилспиро[2Н-индол-2,3'$[3 \mathrm{H}]$ нафто[2,1-b][1,4]оксазина] (II).<smiles>N#Cc1c(O)ccc2ccc(O)cc12</smiles>

(1)

(2)

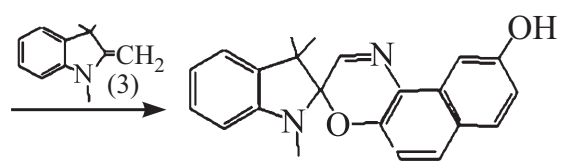

(4)

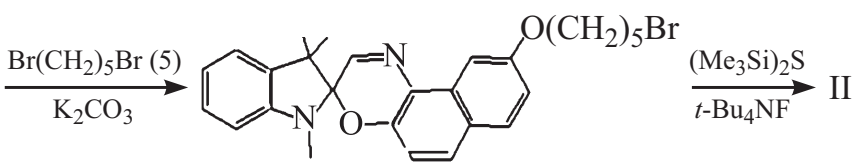

(6)

Схема 4.

В результате предварительного сравнительного исследования нескольких типов промышленно выпускаемых графенов на стабильность дисперсных растворов во времени в качестве объекта была выбрана водная паста графена малослойного G108-2, содержащая 11 вес.\% графена, 2 вес.\% Тритона X-100 (ООО „НаноТехЦентр“, 
Тамбов, Россия). Раствор этой пасты сохранял равномерную сероватую окраску по всему объему с незначительным осадком на дне пробирки и был прозрачным в течение более 200 дней.

Для выявления влияния графена на спектральные свойства соединений готовили смеси растворов выше указанных фотохромных веществ с концентрацией $C=5 \cdot 10^{-4} \mathrm{M}$ в ацетонитриле (безводный, 99.8\%, „Aldrich“) с равным по объему количеством бидистиллированной воды. Все смеси готовили в одинаковых условиях. После проведения спектральных исследований указанные растворы центрифугировали в течение 30-40 min при скорости вращения центрифуги $6000 \mathrm{rev} / \mathrm{min}$. Затем аккуратно отбирали около $0.4 \mathrm{ml}$ надосадочной жидкости и регистрировали ее спектры поглощения, а получившийся осадок наносили на кварцевые пластинки и высушивали при температуре $70^{\circ} \mathrm{C}$.

Образец нанопластинок ОГ, синтезированного по модифицированному методу Хаммерса [19], был предоставлен д.ф.-м.н. В.А. Смирновым из ИПХФ РАН. Физикохимические исследования фотохромных молекул в присутствии ОГ проводили в растворах соединений I и II в безводном ацетонитриле (безводный, 99.8\%, „Aldrich“" с концентрацией $C=4 \cdot 10^{-4} \mathrm{M}$. Эти растворы хорошо смешивались с водой. Нанопластинки ОГ содержались в воде в виде дисперсии. Смеси растворов фотохромных соединений с водой в соотношении 1:1 (по объему) готовили непосредственно перед исследованием. Для этого в объем $0.1 \mathrm{ml}$ бидистиллированной воды добавляли $0.1 \mathrm{ml}$ раствора фотохромного соединения и интенсивно перемешали. Раствор выдерживали в темноте в течение $20 \mathrm{~min}$. По аналогии получали смесь растворов фотохромных соединений с раствором наночастиц ОГ $(C=0.08 \mathrm{mg} / \mathrm{ml})$. Для этого готовили растворы, содержащие фотохромные соединения, бидистиллированную воду и раствор ОГ в соотношении 2:1:1 (по объему) соответственно и выдерживали в темноте в течение не более $20 \mathrm{~min}$.

Спектрально-кинетические исследования фотохромных растворов наночастиц графена и нанопластинок ОГ проводили на установке, созданной на основе спектрофотометра Ocean Optics, в кварцевой кювете марки КУ-1 с длиной оптического пути $2 \mathrm{~mm}$.

Растворы облучали светом ксеноновой лампы L8253 облучателя LC-8 фирмы „Наmamatsu“ при максимальной плотности мощности излучения $\left(\sim 250 \mathrm{~W} / \mathrm{m}^{2}\right)$ через цветные стеклянные светофильтры УФС-1, ЖС-10 и ЖC-16.

\section{Результаты и их обсуждение}

\section{Фотохромные системы на основе наночастиц графена}

Фотоиндуцированные изменения спектров поглощения соединения I в водно-ацетонитрильном растворе в процессе его фотохромных превращений оказались

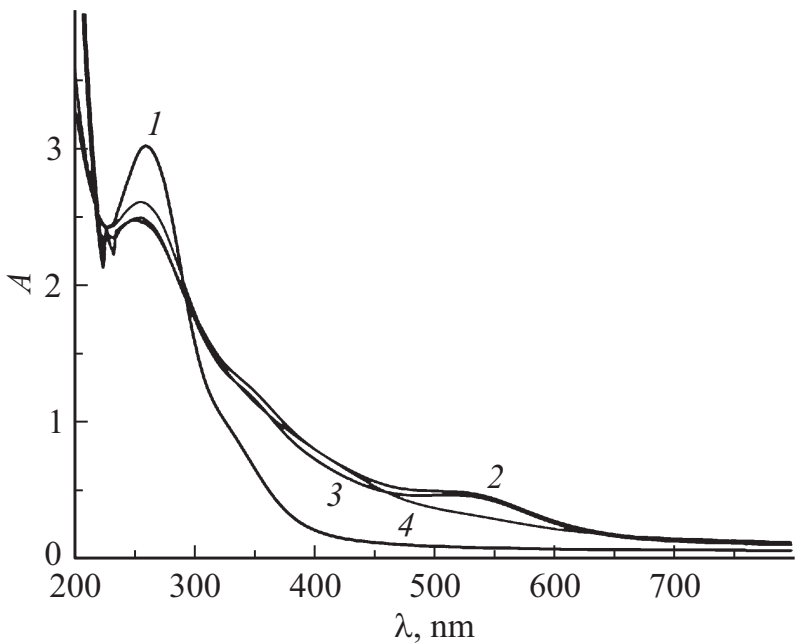

Pис. 1. Спектры поглощения соединения I в надосадочном растворе наночастиц графена G-108 до (1), после УФ облучения через светофильтр УФС-1 (2), в процессе темновой релаксации (3) и последующего облучения видимым светом через светофильтр ЖС-10 (4).

подобными тем, которые наблюдаются в органических растворителях [20]. Диарилэтен I термически необратим и проявляет фотохромные превращения только при облучении светом соответствующего спектрального состава, поглощаемого изомерами А и В (схема 1).

После введения в раствор наночастиц графена максимум полосы поглощения фотоиндуцированной циклической формы диарилэтена гипсохромно смещался на $5 \mathrm{~nm}$ относительно максимума этой полосы поглощения в растворе (рис. 1, таблица). При этом в 2 раза повышалась эффективность процесса УФ окрашивания, оцениваемая по величине соотношения $\Delta D_{\mathrm{B}^{\text {phot }}} / D_{\mathrm{A}^{\max }}$ (таблица). Практически отсутствовала термическая релаксация циклической формы В диарилэтена I в открытый изомер А (рис. 1, ср. 2 и 3). Это превращение наблюдалось только при облучении раствора видимым светом (рис. 1,4 ).

Следует отметить, что наночастицы в присутствии молекул диарилэтена I сохраняли фотохромные свойства после многократной их отмывки растворителем.

В случае твердофазной пленки, полученной из водноацетонитрильной раствора, содержащего наночастицы графена G108-2 и соединения I, обнаружено резкое падение эффективности УФ окрашивания раствора (таблица). При этом по сравнению с раствором максимум полосы поглощения фотоиндуцированной циклической формы сдвигается на $122 \mathrm{~nm}$ в длинноволновую спектральную область (таблица).

Спирооксазин II также проявляет типичные термически обратимые фотохромные превращения [21] как в водно-ацетонитрильном растворе, так и в надосадочной жидкости. Однако для этого соединения не наблюдается каких-либо различий в спектральных свойствах и чувствительности к УФ излучению растворов без и в присутствии наночастиц графена (таблица). Фотохромные 
Спектрально-кинетические характеристики фотохромных соединений в водно-ацетонитрильных растворах и твердофазных слоях без и в присутствии наночастиц графена и ОГ

\begin{tabular}{c|c|c|c|c|c}
\hline Соединение & Наночастицы & Система & $\lambda_{\mathrm{A}^{\max }, \mathrm{nm}}$ & $\lambda_{\mathrm{B}^{\max }, \mathrm{nm}}$ & $\Delta D_{\mathrm{B}^{\text {phot }}} / D_{\mathrm{A}^{\max }}$ \\
\hline I & - & Раствор & 265 & 521 & 0.09 \\
I & Графен & Раствор & 260 & 516 & 0.17 \\
I & Графен & Пленка & $263,310,388$ & 638 & 0.02 \\
II & - & Раствор & 242,338 & 605 & 0.17 \\
II & Графен & Раствор & 239,338 & 605 & 0.17 \\
II & Графен & Пленка & 255,354 & 619 & 0.10 \\
II & - & Пленка & 247,345 & 621 & 0.26 \\
I & ОГ & Раствор & 336 & 528 & 0.29 \\
I & ОГ & Пленка & $237,284,377$ & 481 & \\
II & ОГ & Раствор & 259,335 & 509 & 0.01 \\
II & ОГ & Пленка & $232,254,371$ & 623 & 0.52
\end{tabular}

Примечание. $\Delta \lambda_{\mathrm{A} \max }, \lambda_{\mathrm{B} \text { max }}$ - длины волн максимумов всех полос поглощения исходной и длинноволновых полос поглощения фотоиндуцированных форм фотохромных соединений, соответственно; $D_{\mathrm{A}}$ max - величина оптической плотности в максимуме полосы поглощения исходной формы; $\Delta D_{\mathrm{B}}$ phot - фотоиндуцированное изменение оптической плотности в максимуме полосы поглощения фотоиндуцированной формы в состоянии фоторавновесия.

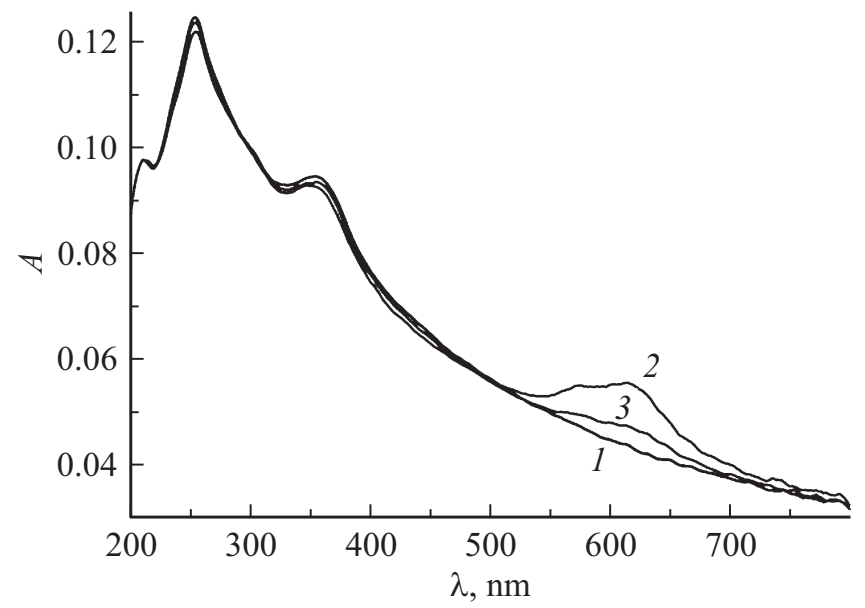

Pис. 2. Спектры поглощения твердотельной пленки, полученной из водно-ацетонитрильной смеси наночастиц графена G108-2 и спирооксазина II до (1), после УФ облучения (2) и в процессе темновой релаксации (3).

свойства наночастиц сохранялись после неоднократной отмывки растворителем.

Твердофазные пленки, полученные из водно-ацетонитрильной смеси наночастиц графена G-108 и соединения II, как и пленки диарилэтена I, характеризуются батохромным спектральным сдвигом максимума фотоиндуцированной полосы поглощения мероцианиновой формы спирооксазина II, правда, на меньшую величину $(18 \mathrm{~nm})$ по сравнению с соответствующим раствором (рис. 2, таблица). Вероятно, это связано с переходом фотохромного соединения в аморфное состояние. В пользу этого свидетельствует то, что подобные спектральные характеристики обнаружены для твердофазной пленки спирооксазина II без графена (таблица).

Одновременно было установлено, что для пленки, полученной из раствора, содержащего смесь наночастиц графена G108-2 и соединения II, наблюдается замедление кинетики процессов фотоокрашивания и темновой релаксации мероцианиновой формы по сравнению с растворами. Для проверки предположения, не является ли это следствием влияния наночастиц графена, была изучена кинетика фотохромных превращений спирооксазина II в твердофазных пленках без и в присутствии графена. Оказалось, что твердофазная пленка, полученная из раствора спирооксазина II без графена, характеризуется более высокой скоростью фотоокрашивания по сравнению с графенсодержащей пленкой (рис. 3, ср. 1 и 3). Это различие можно объяснить снижением интенсивности активирующего излучения изза его поглощения и рассеяния наночастицами графена.

Наибольшее различие обнаружено в кинетике темнового обесцвечивания мероцианиновой формы спироок-

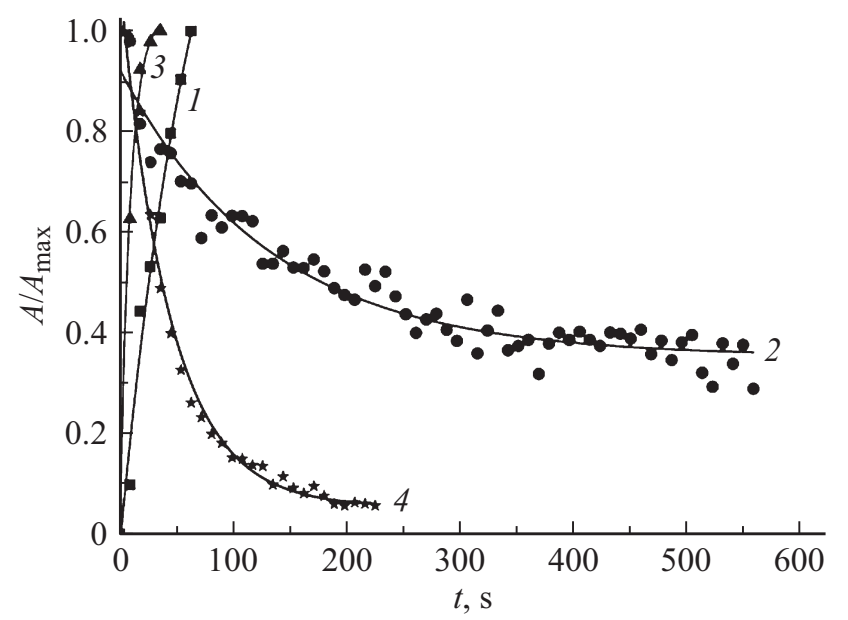

Рис. 3. Нормированные кинетические кривые процессов УФ окрашивания через светофильтр УФС-1 $(1,3)$, темновой спонтанной релаксации $(2,4)$ твердотельной пленки, полученной из раствора, содержащего спирооксазин II и наночастицы графена G-108 $(1,2)$ и твердотельной пленки спирооксазина II $(3,4)$. 
сазина в этих пленках (рис. 3, таблица). В присутствии наночастиц графена скорость темновой релаксации резко падает по сравнению с твердофазными пленками спирооксазина II, не содержащими наночастиц графена (рис. 3, ср. 2 и 4). Эти результаты свидетельствуют о взаимодействии молекул спирооксазина II с поверхностью наночастиц графена G-108.

\section{Фотохромные системы на основе ОГ}

В отличие от наночастиц графена добавление к водноацетонитрильному раствору соединения I раствора нанопластинок ОГ сдвигает полосу поглощения циклической формы диарилэтена I в длинноволновую спектральную область на $7 \mathrm{~nm}$ (рис. 4, таблица).

Добавление раствора нанопластинок ОГ к растворам, содержащим соединение I, вызывает также замедление процесса УФ окрашивания, но практически не сказывается на процессе обесцвечивания под действием видимого света. При этом, как и в случае наночастиц графена, чувствительность к УФ излучению возрастает (таблица).

Для твердофазных пленок ОГ и диарилэтена I наблюдается значительный сдвиг максимума полосы поглощения циклической формы, но в отличие от подобных пленок на основе наночастиц графена не в длинноволновую, а в коротковолновую спектральную область на $49 \mathrm{~nm}$ (таблица). При этом также резко падает чувствительность пленок к УФ излучению.

Анализ разностных спектров фотоиндуцированной формы спирооксазина II, представленных на рис. 5, показывает, что в присутствии в растворе нанопластинок ОГ наблюдается резкий гипсохромный сдвиг максимума фотоиндуцированной полосы поглощения на $95 \mathrm{~nm}$ (рис. 5, таблица). Этот спектральный сдвиг может быть обусловлен протонированием мероцианиновой формы спирооксазина II в результате взаимодействия гидроксильных или карбоксильных поверхностных групп с фенолятным кислородом этой формы [22]. Такое взаимодействие замедляет кинетику процесса темновой релаксации спирооксазина II (рис. 6).

Существенные фотоиндуцированные спектральные и кинетические изменения, наблюдаемые для растворов спирооксазина II в присутствии нанопластинок ОГ являются доказательством специфического взаимодействия молекул этих соединений с поверхностными группами вследствие образования водородных связей и протонирования мероцианиновой формы спирооксазина.

Максимум полосы фотоиндуцированного поглощения твердофазной пленки, состоящей из наночастиц ОГ и спирооксазина II, близок к максимуму соответствующей полосы поглощения, наблюдаемому для твердофазных пленок самого спирооксазина II (таблица). Это предполагает отсутствие водородных связей между молекулами спирооксазина и поверхностными группами ОГ в твердофазной пленке. Как и в остальных случаях, эффективность фотоокрашивания спирооксазина в твердофазных пленках резко снижается (таблица).

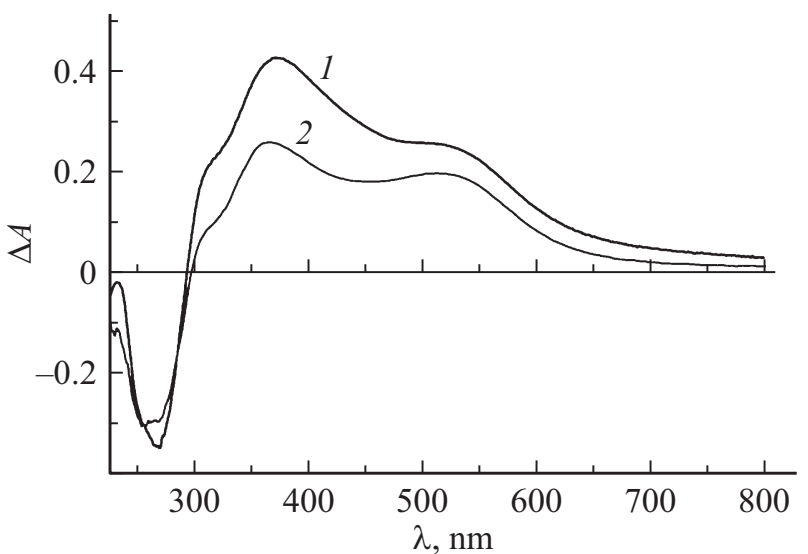

Рис. 4. Разностные спектры поглощения фотоиндуцированной циклической формы соединения I в смеси с водой $(1)$, с водой и раствором нанопластинок ОГ (2).

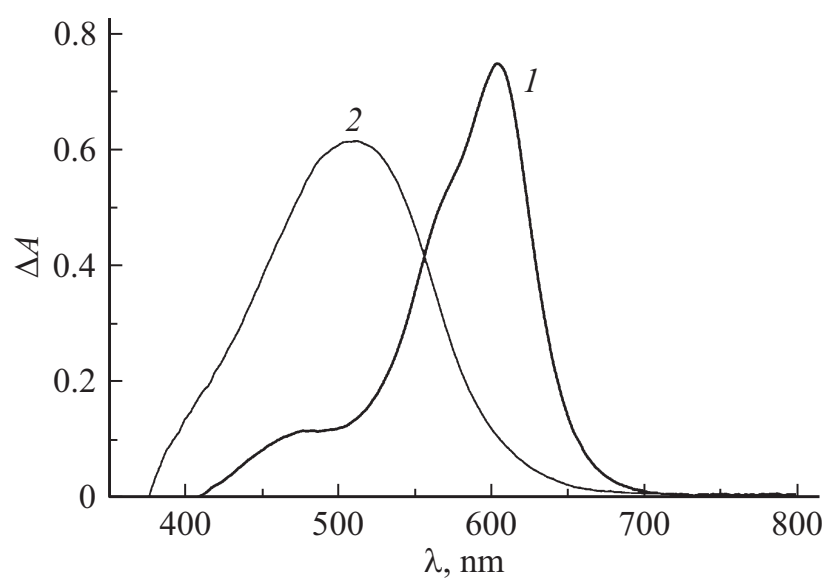

Рис. 5. Разностные спектры поглощения фотоиндуцированной формы соединения II в смеси с водой $(\mathbf{1})$, с водой и раствором нанопластинок ОГ (2).

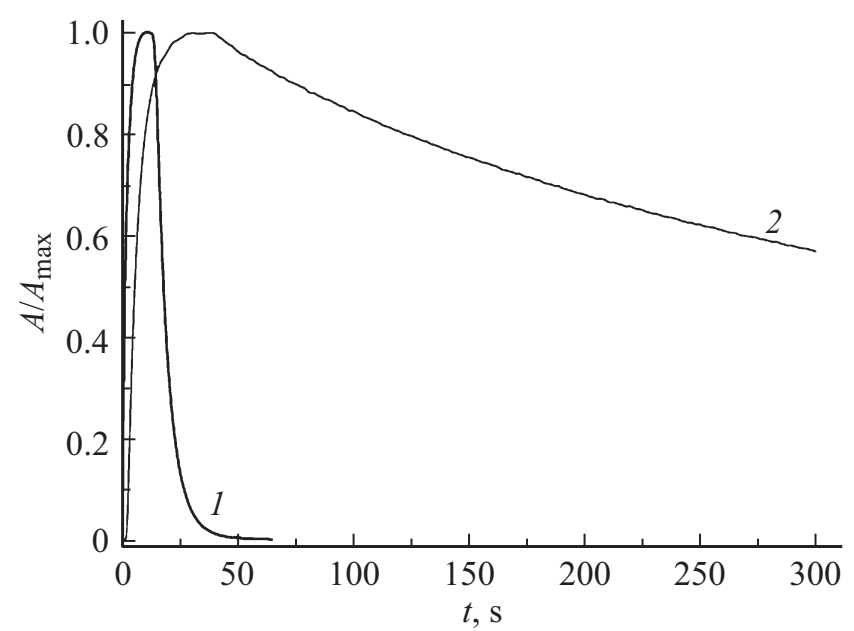

Рис. 6. Нормированные кривые фотоокрашивания УФ светом и термической релаксации спирооксазина II в смеси с водой (1), с водой и раствором ОГ (2). 
Анализ полученных результатов спектрально-кинетического исследования систем на основе нанопластинок графена G-108 и ОГ в присутствии фотохромных соединений из классов диарилэтенов и спирооксазинов, содержащих тиольные заместители, позволяет сделать вывод о возможности функционализации поверхности этих наноструктур фотохромными молекулами вследствие хемосорбции молекул в исходных формах А. В пользу этого свидетельствует невозможность вымывания фотохромных молекул с поверхности наночастиц растворителем, увеличение чувствительности фотохромных соединений к УФ излучению в присутствии наночастиц. Адсорбированные молекулы фотохромных соединений испытывают фотохромные превращения как в растворах, так и в твердофазных слоях. Благодаря гибким спейсерам, содержащимся в структуре, молекулы фотоиндуцированной мероцианиновой формы могут вступать в дополнительное ковалентное и нековалентное взаимодействие с поверхностными группами. О нековалентном взаимодействии фотоиндуцированной мероцианиновой формы спирооксазина II свидетельствует снижение скорости темновой релаксации этой формы В в исходную циклическую форму А в твердофазных пленках, содержащих наночастицы графена. Ковалентное взаимодействие, обнаруженное для молекул мероцианиновой формы тиолзамещенного спирооксазина II, адсорбированных на поверхности нанопластинок ОГ, приводит к образованию протонированных комплексов.

Наблюдаемое для растворов обоих фотохромных соединений снижение скорости фотоокрашивания после введения в раствор наночастиц графена и нанопластинок ОГ, по-видимому, обусловлено снижением интенсивности активирующего УФ излучения за счет рассеяния и поглощения света наночастицами.

Характерное для твердофазных пленок на основе диарилэтена I и спирооксазина II, а также графена батохромное смещение полос поглощения фотоиндуцированных форм объясняется переходом фотохромных соединений в аморфное, а затем в кристаллическое состояние.

\section{Выводы}

В результате впервые проведенного систематического спектрально-кинетического исследования фотохромных систем с использованием тиолсодержащих диарилэтена и спирооксазина, а также наночастиц графена и нанопластинок ОГ показана возможность создания на их основе фотохромных наноструктур, проявляющих фотохромные свойства в растворах и твердофазных слоях. Хемосорбированные тиолсодержащие молекулы в процессе фотохромных превращений могут вступать в дополнительное взаимодействие с поверхностными группами, в частности с образованием протонированных комплексов мероцианиновой формы спирооксазина на поверхности нанопластинок ОГ.

\section{Финансирование работы}

Работа выполнена при поддержке Министерства науки и высшего образования в рамках выполнения работ по Государственному заданию ФНИЦ „Кристаллография и фотоника“ РАН.

\section{Конфликт интересов}

Авторы заявляют, что у них нет конфликта интересов

\section{Список литературы}

[1] Avouris P. // Nano Lett. 2010. V. 10. P. 4285. doi $10.1021 / \mathrm{nl} 102824 \mathrm{~h}$

[2] Туктаров А.Р., Хузин А.А., Джемилев У.М. // Усп. химии. 2017. T. 86 C. 474; Tuktarov A.R., Khuzin A.A., Dzhemilev U.M. // Rus. Chem. Rev. 2017. V. 86. P. 474. doi $10.1070 /$ RCR 4685

[3] Canto E.D., Flavin K., Natali M., Perova T., Giordani S. // Carbon. 2010. V. 48. P. 2815. doi 10.1016/j.carbon.2010.04.012

[4] Khairutdinov R.F., Itkis M.E., Haddon R.C. // Nano Lett. 2004. V. 4. P. 1529. doi $10.1021 / \mathrm{n} 1049538 \mathrm{j}$

[5] Setaro A., Bluemmel P., Maity C., Hecht S., Reich S. //Adv. Funct. Mater. 2012. V. 22. P. 2425. doi 10.1002/adfm.201102451

[6] Guo X., Huang L., O'Brien S., Kim P., Nuckolls C. // J. Am. Chem. Soc. 2005. V. 127. P. 15045. doi 10.1021/ja054335y

[7] Bluemmel P., Setaro A., Maity C., Hecht S., Reich S. // Phys. Stat. Sol. B. 2012. V. 249. P. 2479. doi $10.1002 /$ pssb.201200387

[8] Bluemmel P., Setaro A., Maity C., Hecht S., Reich S. // J. Phys.: Condens. Matter. 2012. V. 24. P. 394005. doi 10.1088/0953-8984/24/39/394005

[9] Malic E., Weber C., Richter M., Atalla V., Klamroth T., Saalfrank P., Reich S., Knorr A. // Phys. Rev. Lett. 2011. V. 106. P. 097401. doi 10.1103/PhysRevLett.106.097401

[10] Malic E., Setaro A., Bluemmel P., Sanz-Navarro C.F., Ordej_on P., Reich S., Knorr A.J. // Phys.: Condens. Matter. 2012. V. 24. P. 394006. doi 10.1088/0953-8984/24/39/394006

[11] Jang A-R., Jeon E.K., Kang D., Kim G., Kim B.-S., Kang D.J., Shin H.S. // ACSNano. 2012. V. 6. P. 9207. doi $10.1021 / \mathrm{nn} 303539 \mathrm{y}$

[12] Joo P., Kim B.J., Jeon E.K., Cho J.H., Kim B. // Chem. Commun. 2012. P. 10978. dx.doi.org/10.1039/C2CC35933B

[13] Bode N., Mariani E., von Oppen F.J. // J. Phys.: Condens. Matter. 2012. V. 24. P. 394017. doi 10.1088/0953-8984/24/39/394017

[14] Berghauser G., Malic E. // Phys. Stat. Sol. B. 2013. V. 250. P. 2678. doi 10.1002/pssb.201300181

[15] Nahain A-A., Lee J.-E., Jeong J.H., Park S.Y. // Biomacromolecules. 2013. V. 14. P. 4082. doi 10.1021/bm4012166

[16] Sharker S.M., Jeong C.J., Kim S.M., Lee J.-E., Jeong J.H., In I., Lee H., Park S.Y. // Chem. Asian J. 2014. V. 9. N 10. P. 2921. doi 10.1002/asia.201402399

[17] Lucas L.N., de Jong J.J.D., van Esch J.H., Kellogg R.M., Feringa B.L. // Eur. J. Org. Chem. 2003. P. 155. doi 10.1002/1099-0690(200301)2003:1<155::AID-EJOC155> 3.0.CO; $2-\mathrm{S}$ 
[18] Барачевский В.А., Кобелева О.И., Валова Т.М., Айт А.О., Кольцова Л.С., Шиенок А.И., Зайченко Н.Л., Лаптев А.В., Ходонов А.А., Кузнецова О.Ю., Дудинов А.А., Личицкий Б.В., Краюшкин М.М. // Теорет. эксп. химия. 2012. Т. 48. С. 12; Barachevsky V.A., Kobeleva O.I., Valova T.M., Ait A.O., Shienok A.I., Zaichenko N.L., Laptev A.V., Khodonov A.A., Kuznetsova O.Yu., Dudinov A.A., Lichitsky B.V., Krayushkin M.M. // Theoret. Exper. Chem. 2012. V. 48. N 1. P. 14.

[19] Мурадян В.Е., Езерская М.Г., Смирнова В.И., Кабаева Н.М., Новиков Ю.Н., Парнес З.Н., Вольпин М.Е. // ЖOX. 1991. T. 61. P. 2626.

[20] Irie M., Fukaminato T., Matsuda K., Kobatake S. // Chem. Rev. 2014. V. 114. N 24. P. 12174.

[21] Minkin V.I. // Chem. Rev. 2004. V. 104. N 5. P. 2751. doi 10.1021/cr500249p

[22] Liu Y., Fan M., Zhang C., Yang W., Zhu L., Zhang G., Shuai Z., Zhou J., Yan W., Fu H., Yao J. // Dyes and Pigments. 2008. V. 76. P. 264. doi 10.1016/j.dyepig.2006.08.041 